\title{
Assessing Pedestrian Environment: A Review on Pedestrian Facilities in Rajshahi City Corporation Area
}

\author{
Aftabun Nahar*, Abdul Mohaimenu Mim, Md. Mostafizur Rahman \\ Department of Urban \& Regional Planning, Rajshahi University of Engineering \& Technology, Rajshahi, Bangladesh \\ Email address: \\ himu2010.13@gmail.com (A. Nahar) \\ ${ }^{*}$ Corresponding author \\ To cite this article: \\ Aftabun Nahar, Abdul Mohaimenu Mim, Md. Mostafizur Rahman. Assessing Pedestrian Environment: A Review on Pedestrian Facilities in \\ Rajshahi City Corporation Area. American Journal of Traffic and Transportation Engineering. Vol. 4, No. 1, 2019, pp. $24-30$. \\ doi: 10.11648/j.ajtte.20190401.14
}

Received: March 3, 2019; Accepted: April 9, 2019; Published: May 15, 2019

\begin{abstract}
Traffic congestion and lack of public pedestrian space are faced by most urban areas in Bangladesh. Provision of facilities for pedestrian is not increased as a rate of increase in population. Consequently pedestrians are at greater risk for their safety, especially in the commercial zones of large cities. In Rajshahi, walkways are constructed recently; but the facilities are not enough for providing friendly environment. The demand for the improvement of pedestrian facilities is raised due to the reasons such as difficulties in crossing busy intersections, conflicts among pedestrians and vehicles, physical barriers, low visibility, improper design of handicapped accessible ramps and so on. The purpose of the study is to assess pedestrian environment to show how extent the pedestrian facilities are friendly for walking. The pedestrian friendly environment is evaluated under five criteria i.e. Connection, Convenience, Convivial, Comfortable and Conspicuousness. Rajshahi City Corporation area is divided into four zones for comparative view of existing pedestrian planning condition such as Residential Zone, Commercial zone, Recreational zone and Industrial zone. For fulfilling the objectives, questionnaire survey has conducted for user perception on pedestrian environment. Sample size was 267 according to the population of RCC area in 2017 with 95\% confidence level. The method of the sampling is random selection. This study reveals that pedestrian environment is not friendly everywhere and worse in commercial zone rather than other three zones. Main lacking of pedestrian friendly environment is Conviviality among five criteria. Pedestrian's recommendation is also included. It is expected that the results will be highly useful for improvement of walkways for efficient, adequate and safer movement of the pedestrians.
\end{abstract}

Keywords: Pedestrian, Walking Environment, Pedestrian Facilities

\section{Introduction}

Walking is undoubtedly the most common and natural travel mode in cities. It is the primary mode of transportation as other transportation modes require walking to support them such as accessing public transport and changing modes of transportation [1]. The promotion of walking reduces carbon footprint of the society and minimizes energy consumption especially the use of non-renewable energy sources [2]. Many illnesses and health issues faced by many people in the modern society such as stress can also be relieved through walking [3]. Encouraging walking can also generate economic activities and promote tourism that increases a city's competiveness [4]. Though walking has a lots of benefits, people are discouraged to use footpath. Pedestrian environment is a vital influencing factor of walking. The factors that mainly affect the pedestrian's situation is the high speed of motorized vehicles; most car drivers ignore their obligation to give priority to pedestrian at an unprotected pedestrian crossing [5]. A friendly environment can encourage pedestrians. The issue of pedestrian friendly environment has been of increasing importance lately in urban planning and design for the reasons of social life, experiential quality, sustainability, economy or health [6]. In terms of the health benefits of walking and changes in the built environment may help people reach their physical activity goals in addition to 
individually oriented behavior-change interventions by promoting sustainable and healthy life style choices. Walking environments or pedestrian environments are spaces that are supposed to facilitate walking or pedestrian movement and activities [7]. Pedestrians in the roadside environment is subjected to a set of several factors significantly affecting perception of safety, comfort and convenience [8]. A pedestrian movement network can be created through reorganizing the existing streets and pavements and the construction of new walkways [9]. Recently, Rajshahi City Corporation has constructed new walkways.

In the last decade Rajshahi has reached a high growth rate which has led to a massive increase in traffic [10]. In Rajshahi city, walking is encouraged through constructing efficient amount of walkways. The behavior of pedestrian toward using walkways depends on the physical environment of it. A friendly environment for pedestrian is necessary to attract people. Given the benefits and advantages in promoting walking, it is worthwhile to investigate whether it is conducive to walking. The study aims to evaluate the quality of the pedestrian environment in Rajshahi city in terms of pedestrian's perception and the relevant urban design qualities. Furthermore, it is interesting to examine and recommend planning and design guidelines and policies for the future pedestrian friendly environment development of Rajshahi City area and to create walkable communities for Rajshahi city.

\section{Methodology}

Rajshahi City Corporation area is selected for this study. Rajshahi is one of the divisional center of Bangladesh [11] and Rajshahi City Corporation is the major divisional headquarter [12]. For the study purposes, the study area is divided into four categories such as residential zone, commercial zone, industrial zone and recreational zone, so that a comparative view of four zones can be presented. Questionnaire survey has been conducted for knowing user perception. Primary and secondary both data are collected for study purposes. A questionnaire has prepared for data collection. Primary data has been collected through site reconnaissance, questionnaire survey and in-depth interviews. In this study, random sampling technique has been used or else it may not fulfill the purpose. Empirical method is used for population prediction. The total sample needed to conduct the study is about 267 with confidence level $95 \%$ and confidence interval 6 which is calculated by using sample calculator.

Secondary data has been collected from online sources and various development authority. Different govt. organization (RDA, RCC etc.) that are associated with the development and management of footpaths or walkways have been visited to collect various documents and data related to footpaths or walkways development in Rajshahi City. Data collected from questionnaire survey and related authority are analyzed by using Excel and SPSS software. Findings are noted down and represented through charts, figures, tables etc.
Recommendation on pedestrian facilities is also found out.

\section{Data Analysis and Result}

This section investigates how the pedestrian environment can be more pedestrian-friendly and the criteria used in pedestrian planning. There are various qualities which can contribute to a pedestrian-friendly environment and the below reviews a range of research carried out on this particular topic. Sarkar has proposed that an 'ideal' pedestrian environment would enable different activities to happen without causing any conflicts amongst various users such as cyclists, pedestrians and drivers [13]. According to Sarkar, a successful pedestrian environment depends on three criteria:

i. An 'user-friendly environment' which can offer various amenities to pedestrian in which designers should aim to make the streetscape user-friendly not only for pedestrians, but also to cater the needs of vehicles.

ii. A 'unique environment' which has high 'legibility'

iii. A 'visually stimulating environment' in which stimulating elements should be incorporated into the design of walkways.

According to Urban Design Compendium (2000), the environment of pedestrian routes can be assessed by five criteria such as connection, convenience, convivial, comfortable and conspicuousness [14]. The assessment under these criteria is discussed following below-

\subsection{Connection}

In order to know the connectivity among the pedestrian routes, respondents are asked the following question -

Does the pedestrian routes connect the places where they want to go?

The answer varies from zone to zone. Following charts (figure 1) show the results of connectivity of footpaths in different zones of RCC area.

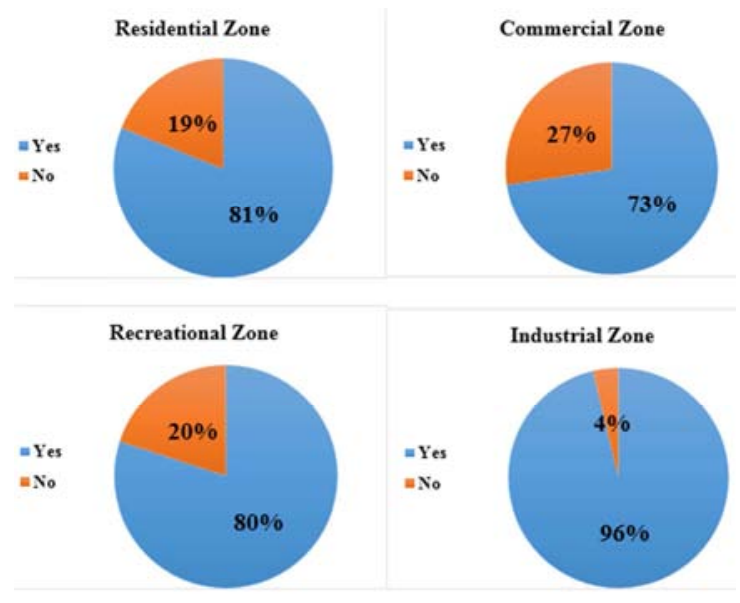

Figure 1. Performance of Connectivity.

In residential zone, $81 \%$ respondents said that the pedestrian routes connects the places where they want to go. 
Only $19 \%$ respondents said that the pedestrian routes does not connect the places where they want to go. So it indicates that the existing connectivity of the pedestrian routes in residential areas is quite good. In commercial zone, $73 \%$ respondents responded with positive answer and only $27 \%$ responded with negative answer. It also denotes that the connection among the pedestrian routes in commercial areas is quite good.

In recreational zone, $80 \%$ respondents agreed with positive answer and $20 \%$ respondents agreed with negative answer. It denotes that the connection rate in the residential areas is also good. And the maximum positive percentages is found in industrial zone (96\%). Therefore, the rate of the connection among the pedestrian routes is so good. If we compare among the four zones, the respondent's answers denoting that connection rate among the pedestrian routes is better in industrial zone than the others three zones.

\subsection{Convenience}

The convenience of walkways is evaluated on the basis of three criteria. These are the straightness of pedestrian routes and the presence of breaking down place in the routes and more waiting time to cross the road. Respondents are asked the following questions -

Are routes direct and are crossings easy to use? Do pedestrians have to wait more than 10 seconds to cross roads?

Residential Zone

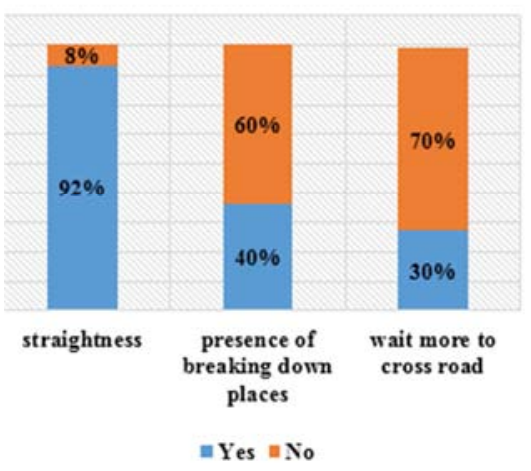

Commercial Zone

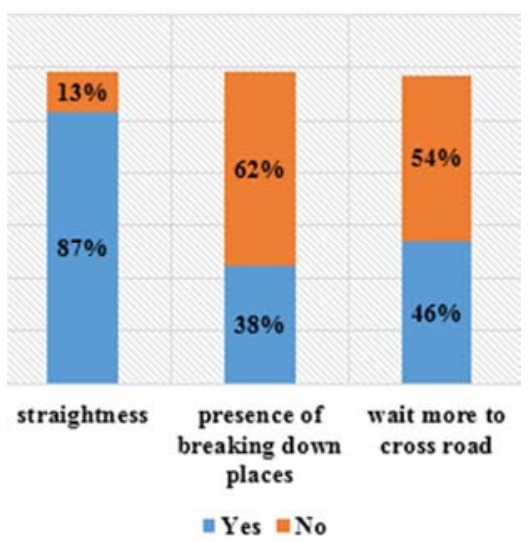

Figure 2. Performance of Convenience in Residential \& Commercial Zone.
The answer varies from zone to zone. Following charts show the results of connectivity of footpaths in different zones of RCC area. According to the figure 2 and 3, maximum pedestrian routes are straight in four zones. But, the scenario of other two criteria is different.

\section{Recreational Zone}

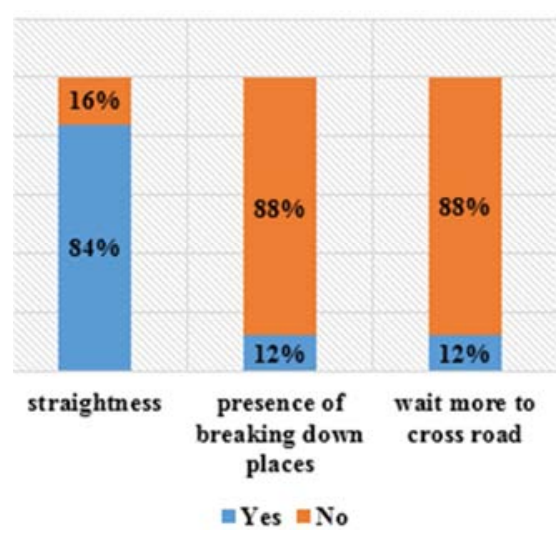

Industrial Zone

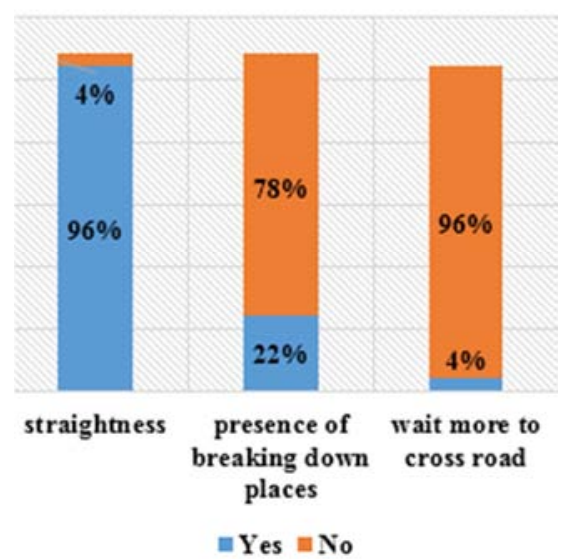

Figure 3. Performance of Convenience in Recreational \& Industrial Zone.

Breaking down places are found in four zones. The percentages is more in residential $(40 \%)$ and commercial (38\%) zone. On the other hand, waiting time is more in commercial zone only. Overall, the convenience of pedestrian routes in industrial zone is better than other three.

\subsection{Convivial}

The rating of the convivial of the pedestrian routes is assessed on the basis of four criteria. These are the attractiveness of the footpaths, livable, endurable and tolerable feelings, security of the area and satisfaction level of existing amenities. In order to know the conviviality among the pedestrian routes, respondents are asked the following questions -

Are routes attractive, well lit and safe, and is there variety along the street?

The answer varies from zone to zone. Following charts show the results of connectivity of footpaths. According to the figure 4 and 5, maximum walkways are attractive and the 

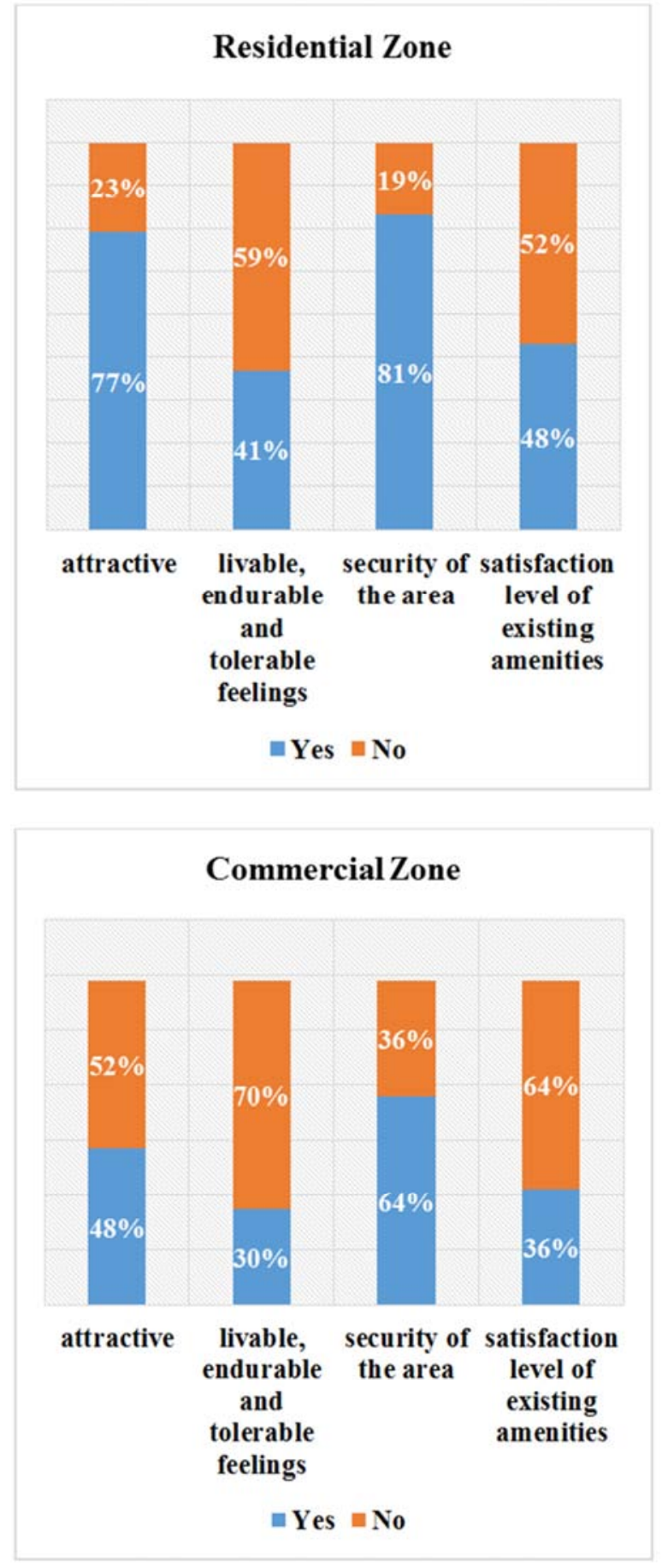

Figure 4. Performance of Conviviality in Residential \& Commercial Zone.

percentages is higher in industrial (96\%), recreational (84\%) and residential zone $(77 \%)$. But the walkways fail to give livable, endurable and tolerable feelings in most of the zone. Security of the area is quite good except commercial zone.

On the other hand, above $50 \%$ satisfaction level of existing amenities of footpaths is found in recreational and industrial zone. Therefore, the conviviality of walkways is better in industrial zone than others.
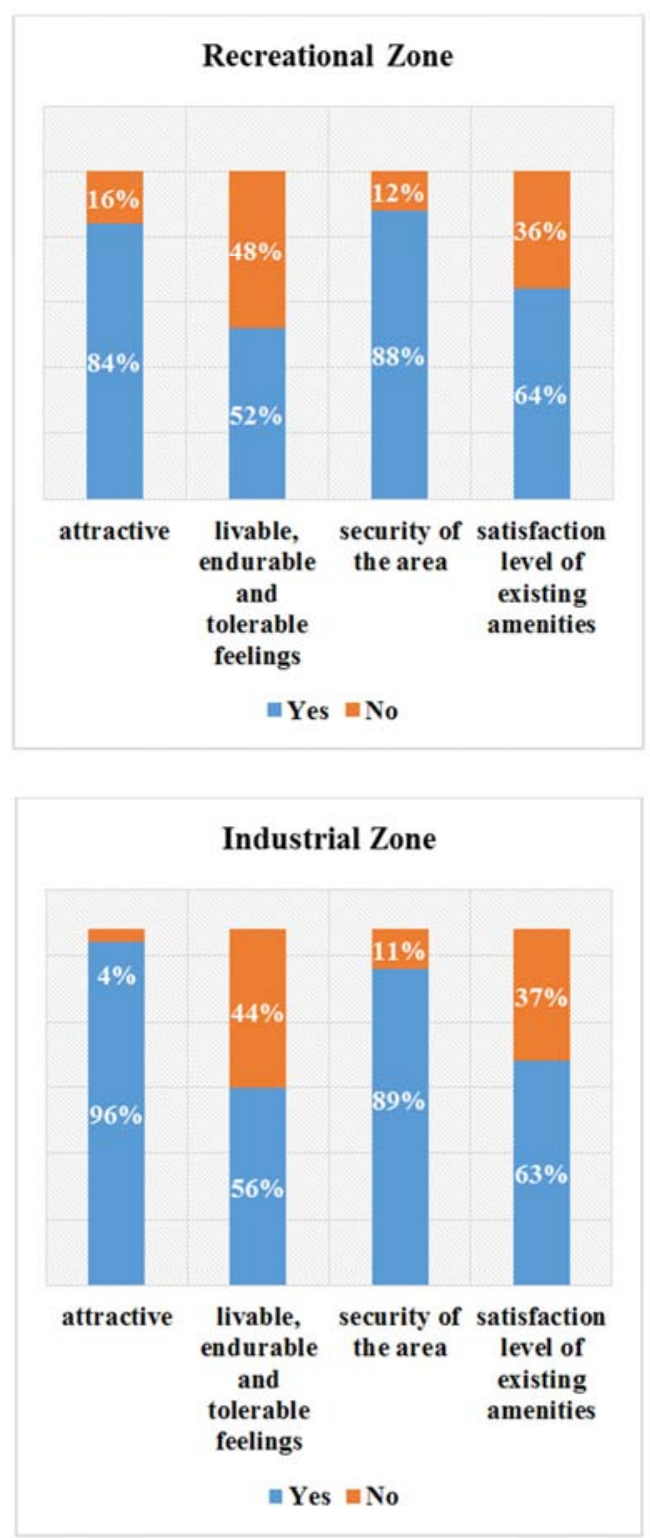

Figure 5. Performance of Conviviality in Recreational \& Industrial Zone.

On the other hand, above 50\% satisfaction level of existing amenities of footpaths is found in recreational and industrial zone. Therefore, the conviviality of walkways is better in industrial zone than others.

\subsection{Comfortable}

The rating on comfortable of the walkways is assessed on the basis of four criteria. These are the satisfaction level with surface quality, comfortable with the width of footpath while walking, secure with the width of footpath and the appearance of any obstacles during walking. In order to know the pedestrian's easement, respondents are asked the following questions -

What is the quality and width of the footway, and what obstructions are there?

Following charts show the results of connectivity of footpaths. 


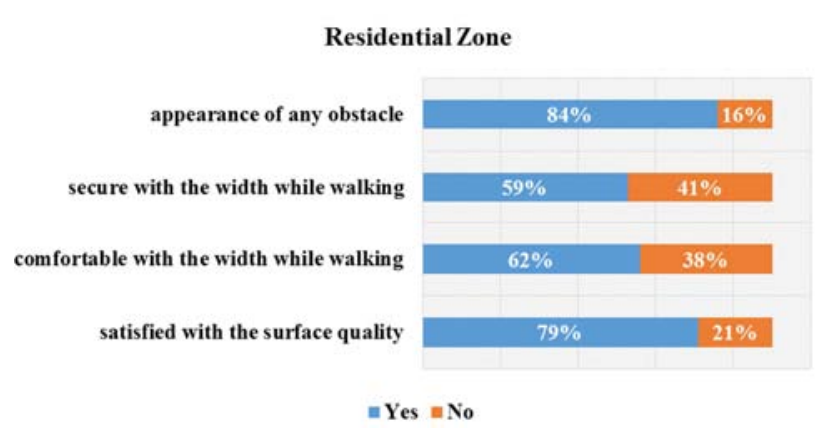

Figure 6. Performance of Comfort in Residential Zone.

In residential zone (figure 6), about $79 \%$ pedestrian is satisfied with the surface quality and $62 \%$ respondents said that they feel comfortable with the width of footpath while walking and $59 \%$ respondent feels secure with the width while walking. As opposed to, in case of facing obstacles the condition is very bad. About $84 \%$ respondents said that they face obstacles.

In case of commercial zone (figure 7), footpaths do not give a pleasant environment for walking comparing to the others. Though the condition of surface quality and comfort of footpath is above $50 \%$, the percentages of security is below 50\%. Moreover, maximum pedestrian (80\%) faces obstacles during walking.

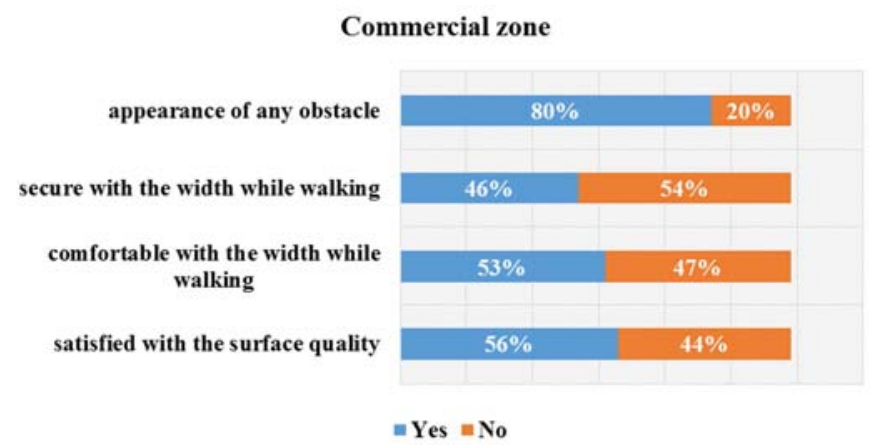

Figure 7. Performance of Comfort in Commercial Zone.

In recreational areas (figure 8), the satisfaction level of surface quality, easement and security of footpath is quite good. On the other side, about $52 \%$ pedestrian faces obstruction.

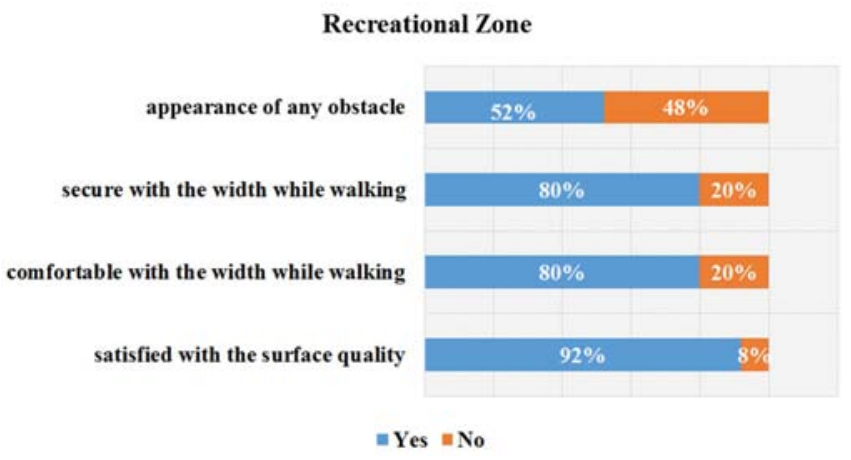

Figure 8. Performance of Comfort in Recreational Zone.

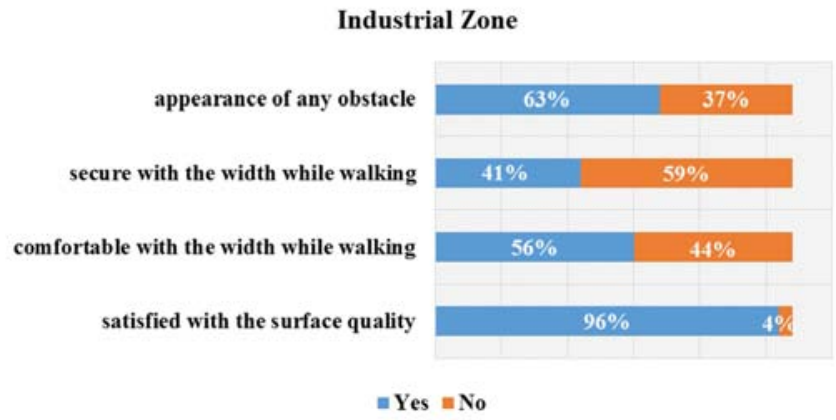

Figure 9. Performance of Comfort in Industrial Zone.

In industrial areas (figure 9), surface quality is very good (96\%). But, quality of other three criteria is not so well. Secure with the width and facing obstacles are not up to the mark. Overall, recreational zone provides more comfort than other three.

\subsection{Conspicuousness}

The rate of the Conspicuousness of the walkways is also evaluated on the basis of four criteria. These are easy to find out and follow the pedestrian routes, proper lighting during night to see footpath, clear view of approaching vehicles during crossing or turning and satisfaction level with the provision of signage. In order to know the connectivity among the pedestrian routes, respondents are asked the following questions -

How easy is it to find and follow a route? Are there surface treatments and signs to guide pedestrians?

Following charts show the results of connectivity of footpaths (figure 10 and 11).

Maximum criteria provide a friendly environment for walking without provision of signage. The overall percentages of easy to find out and follow the pedestrian routes, proper lighting during night to see footpath and clear view of approaching vehicles during crossing or turning is good in RCC area.

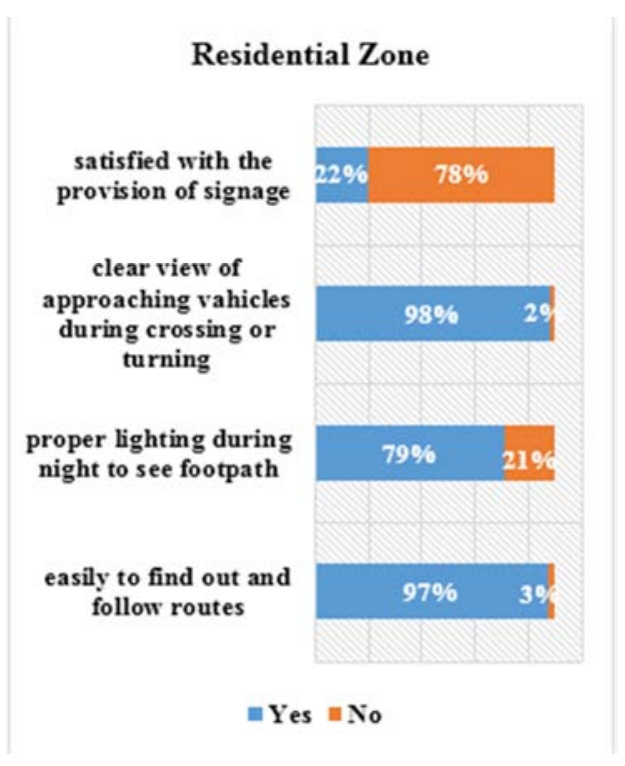




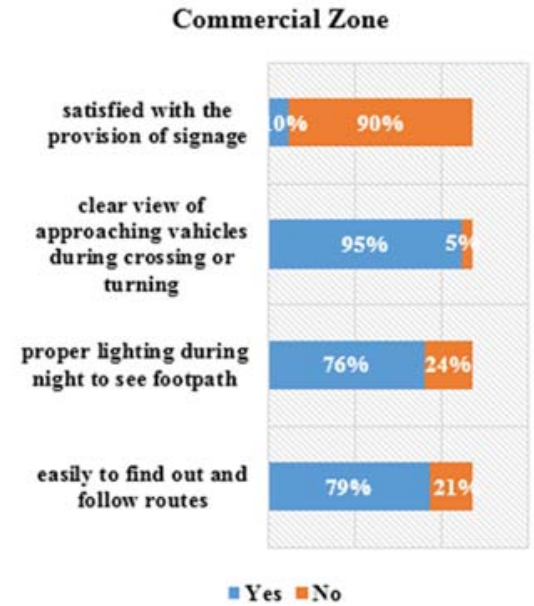

Figure 10. Performance of Conspicuousness in Residential \& Commercial Zone.

The percentage of clear view of approaching vehicles during crossing or turning is more in recreational zone and the percentage of easy to find out and follow the pedestrian routes is more industrial zone. Besides, more than $70 \%$ proper lighting facilities is found to see footpath at night in three zones except recreational.

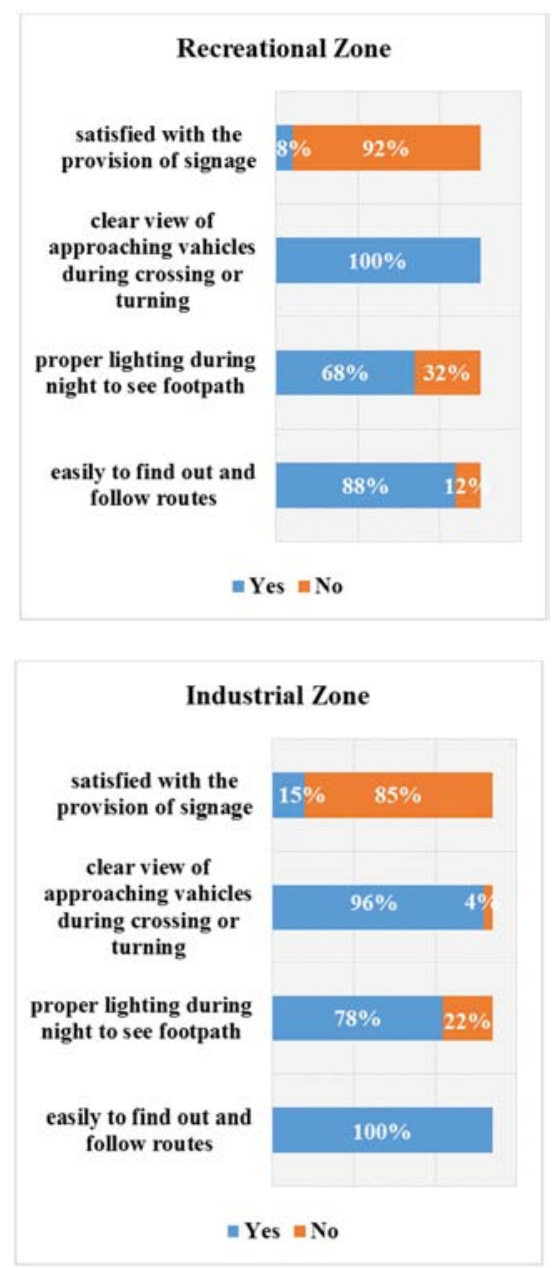

Figure 11. Performance of Conspicuousness in Recreational \& Industrial Zone.

The percentage of clear view of approaching vehicles during crossing or turning is more in recreational zone and the percentage of easy to find out and follow the pedestrian routes is more industrial zone. Besides, more than $70 \%$ proper lighting facilities is found to see footpath at night in three zones except recreational.

\subsection{Pedestrian's Recommendation for Better Environment}

Second portion of questionnaire involves to the recommendation of respondents. Pedestrians are asked for recommendation on facilities which will necessary for betterment of walking environment such as natural shade, facilities for differently able peoples, drinking water facilities, emergency facilities, dustbin, seating arrangement, lighting facilities and others. Multiple responses are found.

\section{Recommendation on Pedestrian Facilities}

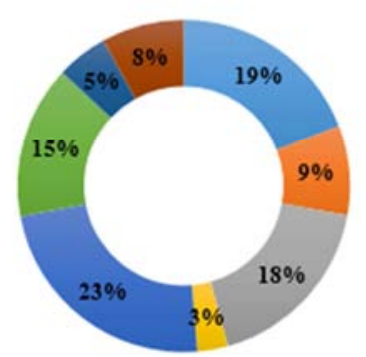

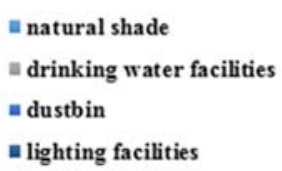

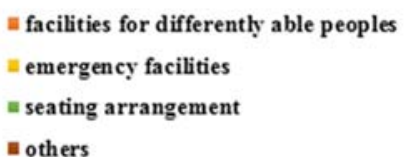

Figure 12. Respondent's Recommendation.

This chart (figure 12) shows that maximum percentage $(23 \%)$ is for dustbin facilities. The second highest facility is natural shade holding $19 \%$. The demand of drinking water facilities $(18 \%)$ is little bit lower than natural shade. Seating arrangement is also recommended by $15 \%$ of respondents. The portion of emergency facilities and lighting facilities is $3 \%$ and $5 \%$ respectively. And the percentage of others facilities is $8 \%$. According to the respondents, others facilities means railing facilities and public toilet facilities.

\section{Conclusion and Recommendation}

According to the questionnaire survey result, the condition of commercial zone is worse than other three. Pedestrian schemes implemented within the study areas that are connected but weak in convivial, conspicuousness, comfortable and convenience. Pedestrian planning in Rajshahi city seems to only focus on getting people from one place to another but neglects the considerations for the quality of walking journeys and promoting walking as an alternative transportation choice. Planning in Rajshahi City has not fully considered pedestrian planning as a form of transport planning when compared to railway and motor 
vehicles. No specific design standards are followed. Although the Authority of Rajshahi City Corporation has started to recognize the importance of pedestrian planning, only piecemeal projects were launched to alleviate the congested pedestrian environment in urban areas.

A common mistake found in the whole study area is separation of footpath from road by providing railing or buffer zone. There are many problems such as lack of facilities, lack of proper maintenance, street vendors, obstacles etc. This study recommends the following steps-

i. Feasible improvement and enhancement plan for current physical pedestrian environment are highly recommend.

ii. Not limited to very small scale of provisions, the pedestrian linkages with necessary facilities should be taken into account for better walkability

iii. Walkways should be provided according to the necessity of the area. Area wise different approach should be taken so that walking can be promoted for all types of walk.

iv. Social Mobility Impacts should also be considered and further modification will be done according to different local contexts

v. Obstruction must be removed such as wastages, street vendors, illegal structures etc

vi. Railing or buffer zone should be provided for segregation of footpath from road.

vii. Some rules and regulations should also be introduced to regulate parking on footpath, street vendors and the users for using walkaways.

viii. Maintenance of footpath is very important. It is possible to enhance walkability and pedestrian environment both by proper maintenance.

This study will help to adopt Proactive Action Plan for Comprehensive Pedestrian Planning in Rajshahi.

\section{References}

[1] Choi, E. (2012). Walkability as an Urban Design Problem (Thesis). KTH Royal Institute of Technology Architecture and the Built Environment, School of Architecture, Sweden.
[2] Holly, I. (2000). Planning of pedestrian environment for Hong Kong's new towns. (Thesis). University of Hong Kong, Pokfulam, Hong Kong SAR.

[3] Nago, W. D. (2003). Improving pedestrian facilities in Hong Kong: A case study of Kwun Tong industrial area. (Thesis). University of Hong Kong, Pokfulam, Hong Kong SAR

[4] Hu, C. (2015). Researches on connections between street design characteristics and pedestrian behaviour. (Thesis). University of Hong Kong, Pokfulam, Hong Kong SAR

[5] Thesis 166 (2007). Pedestrian Safety and Accessibility - A study of the situation at Parnu mnt in central Tallinn. Lund Institute of Technology, Department of Technology and Society Traffic and Road

[6] Galston, R. (2017). Places for People: Designing Pedestrianfriendly Streets in Winnipeg, Manitoba (Thesis). Department of City Planning, The University of Manitoba.

[7] Johnson, E. (2004). WALKABLESTREETS A TOOLKIT FOR OAKLAND. CALIFORNIA: URBAN ECOLOGY

[8] Archana, G. \& Reshma, E. K. (2013). Analysis of Pedestrian Level of Service for Crosswalk at Intersections for Urban Condition. International Journal of Students Research in Technology \& Management, 1 (06), ISSN 2321 -2543, 604 609.

[9] Unterman, R. K. (1984). Accommodating the Pedestrians. New York: Van Nostrand Reinhold Company Limited.

[10] Mandal, S., Ahmed, S. \& Rabbi, F. (2015). Impact of battery driven vehicle on the electricity of Rajshahi city, Bangladesh. International Conference on Mechanical, Industrial and Materials Engineering 2015 (ICMIME2015).

[11] BBS (2011). Population Census, Community Report-Rajshahi, Bangladesh Bureau of Statistics, Government of the People's Republic of Bangladesh.

[12] Rajshahi City Corporation Wikipedia. Retrieved August 30, 2018 from http://en.m.wikipedia.org/wiki/Rajshahi_City_Corporation

[13] Sarkar, M. (1994). A Method for Evaluation of Urban Pedestrian Spaces: UMI Dissertation Services.

[14] Urban Design Compendium. English Partnerships \& the Housing Corporation: UK, 2000. 